\title{
BACTERIOLOGICAL PROFILE AND THE ANTIBIOTIC SUSCEPTIBILITY PATTERN OF ENDOTRACHEAL SECRETIONS IN ICU OF A TERTIARY CARE HOSPITAL
}

\author{
Pooja Gupta1, Shilpa Gupta², Jung Bahadur Singh ${ }^{3}$ \\ ${ }^{1}$ Consultant Microbiologist, Department of Microbiology, Max Super Speciality Hospital, Bathinda, Punjab. \\ ${ }^{2}$ Consultant, Department of Internal Medicine, Max Super Speciality Hospital, Bathinda, Punjab. \\ ${ }^{3}$ Consultant, Department of Internal Medicine, Max Super Speciality Hospital, Bathinda, Punjab.
}

\section{ABSTRACT}

\section{BACKGROUND}

Patients on mechanical ventilation are at higher risk of acquiring hospital acquired infection due to interplay of compromise $d$ host defense, virulent organism and presence of invasive device. Knowledge of local bacteriological trend of the antibiotic susceptibility pattern is a must to initiate a judicious antibiotic treatment.

\section{MATERIALS AND METHODS}

The study was a retrospective descriptive study analysis of endotracheal (ET) samples of patients on mechanical ventilation done over a period of 6 months from July 2017 to Dec 2017. This was done to analyse bacteriological profile and their antibiotic susceptibility.

\section{RESULTS}

44 out of 82 samples showed growth accounting for total of 53\% (positive cultures). Gram negative bacteria were the most common isolates with Klebsiella spp. being the most common bacteria followed by Pseudomonas aeruginosa. Acinetobacter baumannii, though the most resistant organism was a rare isolate. Klebsiella was the most common as well as an MDR (multidrug resistant) isolate.

\section{CONCLUSION}

Gram negative bacteria are the major isolates from ET secretions of patients on mechanical ventilation in our ICU setup, Klebsiella being the most common and resistant too. An antibiogram specific for healthcare setting is a must that shall be based on bacteriological profile and organism's sensitivity pattern.

\section{KEYWORDS}

Endotracheal Aspirate, MDR, Klebsiella Pneumoniae, Mechanical Ventilation, Gram Negative Bacteria.

HOW TO CITE THIS ARTICLE: Gupta P, Gupta S, Singh JB. Bacteriological profile and the antibiotic susceptibility pattern of endotracheal secretions in ICU of a tertiary care hospital. J. Evolution Med. Dent. Sci. 2018;7(18):2210-2213, DOI: $10.14260 /$ jemds/2018/497

\section{BACKGROUND}

Invasive devices continue to be essential for the management of critically ill patients, despite breath-taking advances in modern day medicine. ${ }^{1}$ These ubiquitous devices unfortunately are a major cause of nosocomial infections, especially in the ICU. ${ }^{2}$ As a result following these invasive methods, the incidence of nosocomial infections in ICU has raised. ${ }^{3}$

These infections are associated with significant rise in morbidity, mortality and healthcare cost. An additional problem is the emergence and rise in multi-drug resistant (MDR) pathogens. Several factors like new mutations, selection of resistant strains and suboptimal infection control along with the use high level antibiotics influences the rapid spread of MDR bugs in the ICU. ${ }^{4}$ In patients on mechanical ventilation with intubation, frequent colonisation occurs either through exogenous or endogenous origin. ${ }^{5}$

'Financial or Other Competing Interest': None.

Submission 17-03-2018, Peer Review 12-04-2018,

Acceptance 18-04-2018, Published 30-04-2018.

Corresponding Author:

Dr. Pooja Gupta,

Consultant Microbiologist,

Department of Microbiology,

Max Super Speciality Hospital,

Bathinda-151001, Punjab.

E-mail:Pooja.Gupta@maxhealthcare.com

DOI: $10.14260 /$ jemds $/ 2018 / 497$
Ventilator-associated pneumonia (VAP) is the secondmost common hospital-acquired infection (HAI), accounting for $15 \%$ of HAIs and has the highest morbidity and mortality. ${ }^{6}$ A large number of bacteria are found to be causative factors for colonisation that may later proceed to infection. ${ }^{7}$ Gram negative bacteria are predominant ones. Most common gramnegative bacteria are Pseudomonas aeruginosa, Acinetobacter spp. and Klebsiella pneumoniae.8,9 Prolonged hospital stay and colonisation with Pseudomonas species itself is an independent risk factor for gram negative bacterial infection.

The longer the hospital stay is as in case of head trauma, the more are the chances of change of bacterial flora causing infection, thereby complicating therapy because of alteration of susceptibility pattern. ${ }^{10,11}$

It is very essential for the clinicians to be aware of local bacteriological flora and their susceptibility pattern to encourage rational use of antibiotics. The aim of our study was to present a data that represents the local bacterial trend in respiratory secretions of the ventilated patients and their antibiotic susceptibility patterns.

\section{MATERIALS AND METHODS}

The study was a retrospective descriptive study conducted in 2 ICUs; medical (MICU) and surgical (SICU) of a tertiary care hospital over a period of six months from July 2017 to Dec 2017. The analysis of the reports was done at the Microbiology Department. 
Samples were endotracheal secretions collected from patients, who were on mechanical ventilation for more than 2 days for various reasons. Patients were selected regardless of age and sex. Samples were aseptically inoculated on blood agar and MacConkey agar. The plates were further incubated aerobically at $37^{\circ} \mathrm{C}$ overnight. Significant growth was considered when $>10^{5}$ colonies were obtained from tracheal secretions. ${ }^{12}$ The antibiotics were used as per the strips suitable for the kind of growth as per standard protocol.

A total of 82 samples were collected during the study period. A total of 44 samples showed significant growth when cultured using standard microbiological techniques. ${ }^{13}$ Significant growth was considered when $>10^{5}$ colonies were obtained. ${ }^{12}$ Organisms were identified by automated system; ATB reader and their antibiotic susceptibility was done as per latest CLSI guidelines 2017.14 Exclusion criteria were the isolates identified as contaminant or same isolates from repeat culture of patient. Our gram negative bacterial isolates were defined as multi-drug resistant (MDR) when they were resistant to at least 3 different types of antimicrobials. ${ }^{15}$

\section{RESULTS}

The percentage of positive cultures was approximately 53\% (44 positive cultures out of 82 samples). The most common bacteria isolated were Klebsiella pneumoniae (50\%), Pseudomonas aeruginosa (25\%), Escherichia coli (9\%), Enterococcus faecalis (9\%), Staphylococcus aureus (4.5\%) and Acinetobacter baumannii (2.5\%). Thus, gram negative bacteria (GNB) contributed to major number of isolates (86.5\%); the remaining $13.5 \%$ was as a result of gram positive infections. Moreover, amongst GNB, Enterobacteriaceae ( $K$. pneumoniae and $E$. coli) accounted for 59\%, while non-fermenters (P. aeruginosa and A. baumannii) comprised the rest (Fig. 1).

ICU wise, the common isolates in MICU were Pseudomonas and E. coli followed by Klebsiella, while in
NSICU Klebsiella pneumoniae was the most common isolate. The only Acinetobacter isolate was isolated from NSICU.

\begin{tabular}{|c|c|c|}
\hline $\begin{array}{c}\text { ACTINOBACTER } \\
\text { BAUMANNII } \\
2 \%\end{array}$ & (ICU) endotracheal & $\begin{array}{cc}\text { Secretion, }[n=44] & \begin{array}{r}\text { STAPH } \\
\text { AUREUS } \\
5 \%\end{array}\end{array}$ \\
\hline $\begin{array}{l}\text { ENTEROCOCCUS } \\
\text { FAECALIS } \\
9 \% \\
\\
\\
\text { PSEUDOMONAS } \\
\text { AERUGINOSA } \\
25 \%\end{array}$ & $\begin{array}{l}\text { KLEBSIELLA } \\
\text { PNEUMONIA } \\
50 \%\end{array}$ & 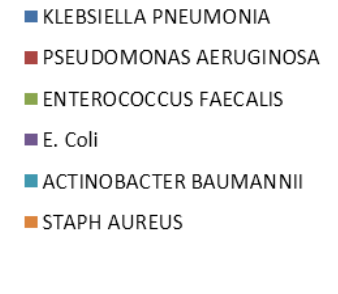 \\
\hline
\end{tabular}

Figure 1. Bacteriological Profile of ET Secretions in MICU and NSICU

\section{Antibiotic Susceptibility Profile}

Amongst gram negative bacteria, E. coli was the least resistant organism being sensitive to aminoglycosides and cotrimoxazole followed by P. aeruginosa. On the other hand, Klebsiella isolates and Acinetobacter spp. were resistant to lower antibiotics namely cephalosporins, aminoglycosides and fluoroquinolones. While some $K$. pneumoniae isolates showed susceptibility to Tigecycline and few to carbapenems, A. baumannii was only sensitive to polymyxins.

Amongst gram positive bacteria, $100 \%$ susceptibility was shown to higher antibiotics viz. teicoplanin, linezolid and Vancomycin, while resistance was observed towards beta lactam antibiotics. The resistance was high towards fluoroquinolones for both gram positive and gram-negative isolates (Table 1).

None of the patients who were mechanically ventilated in our study period developed VAP.

\begin{tabular}{|c|c|c|c|c|c|}
\hline & Pathogens & $\begin{array}{c}\text { No. of } \\
\text { Isolates }\end{array}$ & $\begin{array}{c}\% \text { of } \\
\text { Isolates }\end{array}$ & Sensitive & Resistant \\
\hline 1. & Klebsiella & 22 & 50 & $\begin{array}{c}\text { PB, Col (100\%) } \\
\text { Tgc- }(70 \%), \text { I, Mr (55\%) }\end{array}$ & $\begin{array}{l}\text { All cephalosporins, } \\
\text { aminoglycosides, FQ }\end{array}$ \\
\hline 2. & Pseudomonas & 11 & 25 & $\begin{array}{c}\text { PB, Col (100\%), I, Mr (100\%), CfS } \\
(100 \%), \text { Ak (50\%), PTz (50\%) }\end{array}$ & $\begin{array}{l}\text { Cephalosporins (100\%), FQ } \\
(100 \%), \text { CoT }(100 \%)\end{array}$ \\
\hline 3. & Enterococcus faecalis & 4 & 9 & $\begin{array}{c}\text { Va, Lz, Tei (100\%), PTz (50\%), Tetra } \\
(70 \%),\end{array}$ & Beta Lactams (100\%), FQ (100\%) \\
\hline 4. & E. coli & 4 & 9 & $\begin{array}{c}\text { Col (100\%), I/Mr (100\%), PTz (75\%), } \\
\text { CfS (75\%), Ak (50\%), }\end{array}$ & Amc, Cip, CoTri \\
\hline 5. & S. aureus & 2 & 4.5 & $\begin{array}{c}\text { Va, Lz, Tei (100\%), PTz (50\%), Tetra } \\
\text { (70\%), I (100\%), CD-60\% }\end{array}$ & Cz, E, Cip, Penicillin \\
\hline 6. & A. baumannii & 1 & 2.5 & PB, Col (100\%) & $\begin{array}{c}\text { Carbapenems, FQ, Aminoglycosides, } \\
\text { cephalosporins }\end{array}$ \\
\hline 7. & No growth & 38 & & & \\
\hline \multicolumn{6}{|c|}{ Table 1. Antibiotic Susceptibility Profile of Isolates in ET Secretions } \\
\hline
\end{tabular}

$\mathrm{AK}=$ Amikacin, $\mathrm{GEN}=$ Gentamycin, $\mathrm{CIP}=$ Ciprofloxacin, $\mathrm{IMI}=$ Imipenem, $\mathrm{AMC}=\mathrm{Amox}=\mathrm{co}=\mathrm{Clavulanate}, \mathrm{COT}=\mathrm{Cotrimoxazole}, \mathrm{PB}=$ Polymyxin B, Col= Colistin, Mr= Meropenem, FQ= Fluoroquinolones (Ciprofloxacin, Ofloxacin), $\mathrm{PTz}($ Piperacillin=tazobactam), Va= vancomycin, $\mathrm{Lz}$ (linezolid), Tei= teicoplanin, tetra= tetracycline, $\mathrm{Cz}=$ (cefazolin). 


\section{DISCUSSION}

Endotracheal intubation and mechanical ventilation are lifesaving procedures done to prevent or combat respiratory failure. ${ }^{16}$ On the other hand, it may even lead to lifethreatening lung infections due to various reasons that bypass the host's immune response, whereby organisms enter the airways by exogenous or endogenous route causing ventilator associated pneumonia (VAP). In our study, we chose samples from the patients who were on mechanical ventilation for more than 2 days. This would help us identify VAP.

During our study period, the VAP count was 0 as per the CDC definition. Joseph et al study in Pondicherry showed a high incidence rate of 22.4 per 1000 ventilator days. ${ }^{17}$

There have been many studies done in the Indian subcontinent that have identified the aetiological agents of VAP as well as the susceptibility pattern which has been showing increasing resistance. Most common VAP pathogens are $P$. aeruginosa, Acinetobacter spp., E. coli, K. pneumoniae and $S$. aureus. ${ }^{15}$ In our study, though Klebsiella spp. was the most common organism. Nishat et al study had Pseudomonas, Acinetobacter spp. and Klebsiella pneumoniae as most common isolates (26\% each) followed by $E$. coli and $S$. aureus(15) and $86.3 \%$ isolates were MDR. In our study Klebsiella and Acinetobacter spp. were MDR, while rest of the isolates were quite sensitive except to the beta-lactam antibiotics and fluoroquinolones. In Anusha et al study, Klebsiella was the most common bacteria followed by Pseudomonas, Acinetobacter and E. coli, just like our findings. ${ }^{16}$ But their isolates were mostly susceptible to aminoglycosides and carbapenem class. In our study, Klebsiella isolates were resistant to aminoglycosides.

Summaiya $\mathrm{M}$ et al, while assessing biofilm formation by VAP aetiological agents found that the most common isolates are Pseudomonas aeruginosa and Acinetobacter spp. 18 While Trilok Patil study at Aurangabad found Pseudomonas aeruginosa to be the most common organism (37.4\%) followed by Klebsiella pneumoniae (28.5\%). ${ }^{19}$ George P et al study had Acinetobacter as the most common isolate (37.5\%) followed by Pseudomonas (21.8\%) and Klebsiella (5\%). ${ }^{20}$ These studies differed from our observation of Klebsiella being the most common organism in endotracheal secretions. As per Deepti et al study, Gram negative enteric aerobic bacteria were isolated from most of the patients, most common being Klebsiella species (32.35\%) followed by Acinetobacter and Pseudomonas. ${ }^{21}$ In their study Gram positive cocci were mostly sensitive to Penicillin derivatives, Vancomycin and Clindamycin, while our GPC were resistant to Penicillin derivatives. ${ }^{21}$ These variations in the aetiological bacteria can be due to varied population in ICU, their prior antibiotic therapy and the commensal carriage.

Gram negative bacteria as the most common isolates in ET secretion was similar in various studies, but the multidrug resistant property of Klebsiella isolates and resistance of gram positive bacteria to penicillins in our study is alarming.

The limitation of the study is that the study was of short duration and a retrospective one. The results are not applicable to generalised healthcare settings, since the findings are from a single tertiary care hospital. The BAL sample was not included in samples and the outcome of patients could not be monitored.

\section{CONCLUSION}

Gram negative bacteria form the predominant isolates in our ICU setup; the worrisome being Klebsiella isolates which were resistant to even carbapenem group of antibiotics. Clinicians shall be aware of local bacteriological profiles and their antibiotic sensitivity pattern since that helps them in initiation of an appropriate antibiotic therapy. Thus, an updated antibiogram for a hospital and timely ET secretion culture are the keys to reduce emergence of resistant microbes in patients on mechanical ventilation.

\section{REFERENCES}

[1] Safdar N, Crnich CJ, Maki DG. Nosocomial infections in the intensive care unit associated with invasive medical devices. Curr Infect Dis Rep 2001;3(6):48795.

[2] Anonymous, National Nosocomial Infections Surveillance (NNIS) system report, data summary from Jan 1992-April 2000. Am J Infect Control 2000;28:429-48.

[3] Mehta A, Rosenthal VD, Mehta Y, et al. Device associated nosocomial infection rates in intensive care units of seven Indian cities. Findings of the international nosocomial infection control consortium (INICC). J Hosp Infect 2007;67(2):168-74.

[4] Brusselaers N, Vogelaers D, Blot S. The rising problems of antimicrobial resistance in the intensive care unit. Ann Intensive Care 2011;1:47.

[5] Vadivoo NS, Santharam P, Sudha K, et al. Dynamic bacterial profile of endotracheal aspirates and its sensitivity pattern-a cause of concern. Int J Curr Res Rev 2014;6(10):112-9.

[6] Fiel S. Guidelines and critical pathways for severe hospital-acquired pneumonia. Chest 2001;119(2):412S-8.

[7] Mukhopadhyay C, Bhargava A, Ayyagari A. Role of mechanical ventilation and development of multidrug resistant organisms in hospital acquired pneumonia. Indian J Med Res 2003;118:229-35.

[8] Bonten MJ, Kollef MH, Hall JB. Risk factors for ventilator associated pneumonia: from epidemiology to patient management. Clin infect Dis 2004;38(8):1141-9.

[9] Tullu MS, Deshmukh CT, Baveja SM. Bacterial profile and antibiotic susceptibility pattern in catheter related nosocomial infections. JPGM 1998;44(1):7-13.

[10] Gotsman MS, Whitby JL. Respiratory infections following tracheostomy. Thorax 1964;19(1):89-96.

[11] Kaul S, Brahmadathan KN, Jagannati M, et al. One year trends in the gram-negative bacterial antibiotic susceptibility pattern in a medical intensive care unit in South India. Indian J Med Microbiol 2007;25(3):230-5.

[12] Tablan OC, Anderson LJ, Besser R, et al. Guidelines for preventing health-care-associated pneumonia, 2003: recommendations of CDC and the healthcare infection control practices advisory committee. MMWR Recomm Rep 2004;53(RR-3):1-36. 
[13] Collee JG, Marr W. Culture of bacteria. In: Marmion BP, Fraser AG, Simmons A. (eds). Mackie and Mccartney's practical medical microbiology. $14^{\text {th }}$ edn. New York: Churchill Livingstone, 1996:113-30.

[14] Clinical and laboratory standards institute (CLSI). Performance standards for antimicrobial susceptibility testing; twenty seventh informational supplement. CLSI document 2017:M100-S26.

[15] Ahmed NH, Hussain T, Biswal I. Antimicrobial resistance of bacterial isolates from respiratory secretions of ventilated patients in a multi-specialty hospital. Avicenna J Med 2015;5(3):74-8.

[16] Anusha N, Madhu KP, Arun BJ, et al. Microbiological profile and sensitivity pattern of endotracheal secretions in mechanically ventilated patients in ICU. Journal of Evidence Based Medicine And Healthcare 2014;1(9):1177-84.

[17] Joseph NM, Sistla S, Dutta TK, et al. Ventilatorassociated pneumonia in a tertiary care hospital in India: incidence and risk factors. J Infect Dev Ctries 2009;3(10):771-7.
[18] Summaiya MA, Urmi JN. Assessment of biofilm formation by the causative organisms of ventilator associated pneumonia at intensive care unit of a tertiary care hospital. Natl J Med Res 2012;2(1):15-8.

[19] Patil T. The study of the organisms colonizing trachea in mechanically ventilated patients admitted in the intensive care unit (ICU). International Journal of Medical Science and Education 2014;1(1).

[20] George P, Sequiera A. Antimicrobial sensitivity pattern among organisms which were isolated from the endotracheal aspirates of patients with ventilator associated pneumonia. J Clin Diag Res 2010;4(6):3400-404.

[21] Chandra D, Laghawe A, Sadawarte $K$, et al. Microbiological profile and antimicrobial sensitivity pattern of endotracheal tube aspirates of patients in ICU of a tertiary care hospital in Bhopal, India. Int J Curr Microbiol App Sci 2017;6(3):891-5. 